\title{
Unliganded TRs regulate growth and developmental timing during early embryogenesis: evidence for a dual function mechanism of TR action
}

\author{
Paul M Yen
}

\begin{abstract}
Recent genetic studies in the anuran Xenopus tropicalis reveal surprising new roles of thyroid hormone receptor in regulating growth and developmental timing in the absence of thyroid hormone.
\end{abstract}

Keywords: Thyroid hormone receptor, Vertebrate postembryonic development, Developmental timing, Organogenesis

\section{Text}

Thyroid hormone $\left(\mathrm{T}_{3}\right)$ regulates adult metabolism and postembryonic development in vertebrates [1]. $\mathrm{T}_{3}$ functions mainly by binding to its receptors (TRs) to regulate gene expression. There are two TR genes, TR $\alpha$ and TR $\beta$, with TR $\alpha$ expressed more ubiquitously and earlier during development than TR $\beta$. TRs regulate target gene transcription in a $\mathrm{T}_{3}$-dependent manner. For $\mathrm{T}_{3}$-inducible genes that are positively regulated, TRs recruit coactivator and corepressor complexes in the presence and absence of $T_{3}$, respectively. This leads to chromatin remodeling and changes in histone modifications to activate and repress target gene transcription [1-3]. This dual function mechanism suggests that both liganded and unliganded TRs have distinct physiological roles, particularly during embryonic stages when the fetus is exposed to little or no $\mathrm{T}_{3}$.

During mammalian development, TR $\alpha$ mRNA is detected earlier than endogenous $T_{3}$, suggesting that TRs are mainly unliganded during these early stages. However, it has been challenging to ascertain whether unliganded TRs have transcriptional or physiological functions in a convincing manner since the transplacental supply of maternal $T_{3}$ to the fetus complicates any analysis in mammalian systems. In addition, it is difficult

Correspondence: paul.yen@duke-nus.edu.sg

Laboratory of Hormonal Regulation, Cardiovascular and Metabolic Disorders Program, 8 College Road, Level 8D14, Singapore 169857, Singapore to determine the functional role of unliganded TRs since it is not easy to manipulate their actions pharmacologically or genetically due to the uterine enclosure of mammalian embryos.

In two recent articles published in Endocrinology, the laboratories of Yun-Bo Shi of Eunice Kennedy Shriver National Institute Child Health and Human Development, and Daniel R. Buchholz of University of Cincinnati used Xenopus tropicalis as a model system to overcome some of these problems in studying the action of unliganded TRs during embryogenesis. Their findings have revealed novel functions for unliganded TR $\alpha$ in regulating embryonic animal development by taking advantage of the fact that anurans undergo biphasic development before and after metamorphosis. Accordingly, annurans first undergo embryogenesis to produce free-living tadpoles. After a period of growth, the tadpoles metamorphose into frogs via processes that are regulated by $\mathrm{T}_{3}$ [4]. Similar to mammals, TR $\alpha$ mRNA is expressed very early and reaches high levels of expression by the end of embryogenesis when the feeding tadpole is formed and before synthesis of $\mathrm{TH}$ by the mature tadpole. Based on these and other observations, Shi's group proposed a dual function model for TR during frog development over a decade ago [5]. Initially, $\mathrm{T}_{3}$-inducible genes are expressed at basal levels during early embryogenesis when there is little $T_{3}$ and TR expression. At the end of embryogenesis, these genes are no longer needed for 
development; thus, a correspondingly high level of TR expression occurs during this stage in the relative absence of $\mathrm{T}_{3}$ that, in turn, leads to transcriptional repression of target genes. Later, as $\mathrm{T}_{3}$ becomes available, liganded TRs then activate the expression of $\mathrm{T}_{3}$-inducible genes that will play key roles in metamorphosis. Although extensive studies have demonstrated a critical role for liganded TRs in anuran development [6], there has been little direct evidence supporting the involvement of unliganded TRs in the transcriptional regulation of target genes in vivo.

To address this issue, the Shi and Buchholz groups ingeniously made use of the recently developed TALEN (transcriptional activator-like effector nuclease) method to investigate the role of TR $\alpha$ during the development of the diploid anuran Xenopus tropicalis. Both groups independently designed TALENs to specifically to knock down the TR $\alpha$ gene. Using complementary approaches, both teams demonstrated that removing TR $\alpha$ affected developmental timing in premetamorphic tadpoles, causing the animals to initiate metamorphosis earlier than their wild type siblings $[7,8]$. Consistent with the dual function model for TR, $\mathrm{T}_{3}$-target genes were derepressed during the pre-metamorphic stages in TR $\alpha$ knockdown embryos since gene expression was higher than those in wild type embryos that expressed TR $\alpha$ during these same stages. Additionally, the knockdown embryos were resistant to exogenous $\mathrm{T}_{3}$ treatment and underwent delayed metamorphoses. Surprisingly, Shi's group made the unexpected discovery that knockdown of TR $\alpha$ enhanced tadpole growth in premetamorphic tadpoles. This growth most likely occurred due to derepression (i.e., increase) of growth hormone gene expression. These two studies independently demonstrated the validity of the dual function mechanism of TR $\alpha$ during anuran development as they not only showed the critical role of endogenous TR $\alpha$ in mediating the metamorphic effect of $\mathrm{T}_{3}$ but also revealed novel functions of unliganded TR $\alpha$, that control both tadpole growth rate and timing of metamorphosis during postembryonic development.

Vertebrate development is evolutionally conserved with frog metamorphosis resembling the postembryonic development period in mammals as the latter occurs shortly after birth and is accompanied by a burst of high production and circulating levels of $\mathrm{T}_{3}$ [4]. Likewise, during early embryogenesis the fetus is in a relatively "hypothyroid" state as the fetal thyroid gland has not been formed yet and placental deiodinase III protects the fetus from exposure to maternal $\mathrm{T}_{3}$. It is likely that unliganded TR $\alpha$ plays major roles in repressing the transcription of important target genes during this period before they are activated later during pregnancy and the neonatal period. Therefore, the novel findings from these two studies strongly suggest that unliganded
TRs may play similar roles in the regulation of embryo growth and the timing of organ development and maturation in mammals during the stages when TR is expressed but there is little or no fetal exposure to $T_{3}$. They also provide new insight into some of the developmental consequences within the fetus during iodine deficiency during pregnancy, congenital hypothyroidism, and maternal thyroid dysfunction.

\section{Competing interests}

The author declares that he has no competing interests.

\section{Authors' contributions}

Wrote commentary.

Received: 28 January 2015 Accepted: 28 January 2015

Published: 2 March 2015

\section{References}

1. Yen PM. Physiological and molecular basis of thyroid hormone action. Physiol Rev. 2001;81(3):1097-142.

2. Shi YB, Matsuura K, Fujimoto K, Wen L, Fu L. Thyroid hormone receptor actions on transcription in amphibia: The roles of histone modification and chromatin disruption. Cell Biosci. 2012;2(1):42.

3. Sun G, Fu L, Shi Y-B. Epigenetic regulation of thyroid hormone-induced adult intestinal stem cell development during anuran metamorphosis. Cell Biosci. 2014;4:73.

4. Shi Y-B. Amphibian Metamorphosis: From morphology to Molecular Biology. New York: John Wiley \& Sons, Inc.; 1999

5. Sachs LM, Damjanovski S, Jones PL, Li Q, Amano T, Ueda S, et al. Dual functions of thyroid hormone receptors during Xenopus development. Comp Biochem Physiol B Biochem Mol Biol. 2000;126(2):199-211.

6. Buchholz DR, Paul BD, Fu L, Shi YB. Molecular and developmental analyses of thyroid hormone receptor function in Xenopus laevis, the African clawed frog. Gen Comp Endocrinol. 2006;145(1):1-19.

7. Choi J, Suzuki Kl, Sakuma T, Shewade L, Yamamoto T, Buchholz DR. Unliganded thyroid hormone receptor alpha regulates developmental timing via gene repression as revealed by gene disruption in Xenopus tropicalis. Endocrinology. Endocrinology. 2015;156:735-44.

8. Wen L, Shi YB. Unliganded thyroid hormone receptor alpha controls developmental timing in Xenopus tropicalis. Endocrinology. 2015;156:721-34.

doi:10.1186/2045-3701-5-8

Cite this article as: Yen: Unliganded TRs regulate growth and developmental timing during early embryogenesis: evidence for a dual function mechanism of TR action. Cell \& Bioscience 2015 5:8.

\section{Submit your next manuscript to BioMed Central and take full advantage of:}

- Convenient online submission

- Thorough peer review

- No space constraints or color figure charges

- Immediate publication on acceptance

- Inclusion in PubMed, CAS, Scopus and Google Scholar

- Research which is freely available for redistribution 